and Wilcox, it causes a fall in temperature, not by its action on the blood and circulation (as stated by Shoemaker) but by diminishing heat production through its action on the corpus striatum, which is said to be the center for heat production. To a slight extent, it increases heat dissipation, as has been shown by experiments. No effect on respiration is produced, according to Hare, except when it is given in large doses. When toxic doses are administered the breathing becomes rapid and labored and death may be produced by paralysis of the respiratory centers due to primary changes in the blood which so influence oxygenation of the tissues as to afiect these centers. That the action of acetanilid is more pronounced on the blood than on any other part of the system is generally recognized. Consequently, its effects on the circulation, respiration, temperature and elimination are all probably secondary to the blood changes brought about by too large a dosage or by prolonged use. Under its continued use congestion of the liver, kidneys and spleen takes place. Hare has recorded a number of cases in which unfavorable signs have appeared after its use. The dose which most commonly produced the symptoms ranged from three to ten grains (gm. 0.20 to 0.65 ).

Dr. F. E. Clark ${ }^{1}$ states that while it is a valuable medicament, there are certain dangers which have been more or less emphasized in the reports on this preparation, though no more than attend other preparations of the same class. In this connection he emphasizes the importance of care in its employment in the treatment of new patients whose constitutions and idiosynerasies have not been properly studied, necessary precautions have not in all cases been observed in its admin. istration, but in some cases it has been abused. Its value, on the other hand, according to this writer, has been overrated. As the chief untoward effects of acetanilid are on the heart and circulation as a depressant, he recommends that camphor be combined with it as a stimulant or that some form of liquor be used with it. He warns against the use of those proprietary preparations which are constituted prineipally of acetanilid and sodium bicarbonate as being dangerous to a lamentable extent, as soda is not a corrective of the dangers of acetanilid.

MEDICINAL USE.

Internally, acetanilid cxerts an anodyne, sudorific, antipyretic and slightly soporific effect. He goes on to state that as an anodyne, acetanilid is very inferior to the well-established anodynes, no matter what the cause, and that in the treatment of "headaches" it must be remembered that the other ingredients combined with acctanilid are capable of curing the headache, such as caffein or guarana, potassium or sodium bromid. Consequently, he is of the opinion that too much credit is given to acetanilid. In incipient coryzas, in certain bronchial affections and in pharyngitis-called "colds" by the public-acetanilid acts very efficiently, given ordinarily in doses of from 3 to 5 grains (gm. 0.20-0.30) each and re. peated every two or three hours until perspiration is estab. lished. Acetanilid, given in 5 grain $(0.30)$ doses at bedtime, followed by a hot footbath and a hot lemonade, is superior, in Clarke's opinion, to quinin or Dover's powder.

As a soporific, it is of some value, but is less useful than the opiates. Externally employed, it acts aseptically and antiseptically. As an anodyne locally it is of less value than resorcin. As an aseptic, he claims, it is the equal of iodoform, and is devoid of the odor. He recommends it espeecially in the treatment of ulcers of the leg of the varicose variety.

\section{ACETANIIID POISONING.}

That the use of acetanilid as a local application is not without its dangers has been demonstrated by a report of Manasses, ${ }^{2}$ who mentions two cases of acute symptoms of poisoning following the free use of acetanilid as a dusting powder on abraded surfaces in young children. The usual toxic symptoms were produced, such as cyanosis, subnormal temperature and extreme prostration, which, however, were sucessfully combated by stimulants.

1. Boston Med. and Surg. Jour., November, 1904

2. International Med. Bag., May, 1901.
In regard to chronic acetanilid poisoning, we refer to the article by $D$. D. Stewart ${ }^{3}$ in this issue.

It must be kept in mind in preseribing acetanilid mixtures that no action is produced by them on the cure of the disease. They are of value in the treatment of symptoms mainly, such as relieving pain and reducing temperature. Therefore, to obtain permanent results, other measures can be employed which are of greater value. In cases of fevers, according to von Jaksch, the patient is not made better by these drugs, but, on the other hand, convalescence is prolongeu. The effects of antipyretics vary not only with the dose, but, as expressed by Cushny, with the individual patient. Many individuals can take without apparent harm, very large doses of these preparations, while in others minute quantities produce alarming symptoms.

\section{Correspondence}

\section{Skipping Rope Fatalities.}

Niagara Fald,s, N. Y., May 17, 1905.

To the Editor:-Referring to your editorial in THE Jounnar, April 29, p. 1374, I desire to call your attention to the fact that when a girl jumps the rope to break a record the count is only for the number of times that the rope swings under the feet. While the rope is passing over the head and back to the feet a half jump takes place, thus giving the child her balance for the next spring that will throw her feet high enough to clear the rope again. Thus, in order to clear the rope 250 or more times, the same number of half-jumps are required. The succession of rope-jumps has a peculiar jar about it that is a harmful exereise for the body when long continued. When we consider also the rhythmic movement that must of necessity take place to perform such a feat, I think it will be easy to discover that the strain on the body would be like the strain on a long bridge in case an army of men were marched across it all in perfect marching step. It is the long continued unison jar or vibration that does the mischief. When the children skip the rope as they do when they run and let the rope pass under their feet as they step, there is no sudden jar to the body and, further, Iong runs are not made. It is $\mathrm{my}$ belief that rope-jumping should be discouraged by physicians. W. E. McCiresney, M.D.

Ciricago, May 23, $190 \overline{5}$.

To the Editor:-Your point against rope-jumping is well taken. During a period of four years as medical inspector and medical advisor in certain Philadelphia schools I took every opportunity to discourage rope-jumping, and particularly for all girls over 11 years of age. My objection was that that exercise tended to cause displacement of the uterus of adolescent girls. I would urge physicians to discourage rope-jumping.

WiNFIELD S. HALL, M.D.

\section{Marriages}

Jonx M. Boyles, M.D., to Miss Agnes Mattes, both of Shelby, Mo., May 14.

Robert Wood, M.D., Washington, Ind., to Miss Stella Rogers of Indianapolis, April 1.

Bayard G. Keeney, M.D., to Miss Fthel Adams, both of Shelbyville, Ind., June 1.

JAMFs C. MoBLey,'M.D., to Miss Katie Sweets, both of Elizalethtown, Ky., June i.

Edward A. Mayberry, M.D., Enid, Okla., to Mrs. Marie Herrman of Lacy, Okla., May 21.

Freierick C. Poeminer, M.D., to Miss Eleanor Nesbitt, both of Minneapolis, Minn., June 1.

Jayes Winliam McEwan, M.D., to Miss Ethel Bowman, both of Detroit, Mich., May 17.

Harry Gat Field Irvine, M.D., to Miss Etta McCabe, both of Minneapolis, Minn., May 31.

3. See page 1725 . 